\title{
Sphingosine kinase 2 inhibitor ABC294640 displays anti-epithelial ovarian cancer activities in vitro and in vivo
}

This article was published in the following Dove Press journal: OncoTargets and Therapy

\author{
Keqi Song ${ }^{1,2, *}$ \\ Lan Dai ${ }^{1,2, *}$ \\ Xiaoran Long ${ }^{1,2}$ \\ Xiaojuan $\mathrm{Cui}^{3}$ \\ Yixuan Liu ${ }^{1,2}$ \\ Wen $D i^{1,2,4}$
}

'Department of Obstetrics and Gynecology, Ren Ji Hospital, School of Medicine, Shanghai Jiao Tong University, Shanghai 200127, People's Republic of China; ${ }^{2}$ Shanghai Key Laboratory of Gynecologic Oncology, Ren Ji Hospital, School of Medicine, Shanghai Jiao Tong University, Shanghai 200127, People's

Republic of China; ${ }^{3}$ Department of Obstetrics and Gynecology, Rui Jin Hospital \& Ruijin Hospital North, School of Medicine, Shanghai Jiao Tong University, Shanghai 20180I, People's Republic of China; ${ }^{4}$ State Key Laboratory of Oncogene and Related Genes, Shanghai Cancer Institute, Ren Ji Hospital, School of Medicine, Shanghai Jiao Tong University, Shanghai 200I27, People's Republic of China

*These authors contributed equally to this work

\begin{abstract}
Background: ABC294640 is a non-lipid competitive inhibitor of SphK2. It exhibited antiproliferative activities in many human malignancies, including ovarian cancer. However, its potential mechanism of action remains poorly understood.
\end{abstract}

Methods: In this paper, epithelial ovarian cancer (EOC) cell lines SKOV3 and HO8910 were treated with ABC294640. In order to explore the effect of ABC294640 on the behavior of ovarian cancer cells in vitro, we used cell counting kit-8 (CCK-8) assays, colony formation assays, flow cytometry, quantitative real-time PCR (qRT-PCR), Western blot analysis and immunohistochemistry to detect the effect of ABC294640 on cell proliferation, cell cycle distribution, cell apoptosis, the expression of related factors at mRNA levels, and the expression of related factors at protein level. An intra-abdominal xenograft tumor model of EOC was set up to assess the tumor growth in nude mice.

Results: The results obtained indicate that EOC cell proliferation was noticeably inhibited in a concentration-dependent manner by ABC294640. ABC294640 caused cell cycle arrest in $\mathrm{S}$ phase and increased cell apoptosis rate in EOC cells. Also, the proteins, including phosphorylated retinoblastoma protein $(P-\mathrm{Rb})$, cyclin $\mathrm{D} 1$, cyclin $\mathrm{B} 1$, and $\mathrm{Bcl}-2$ were significantly inhibited, while cleaved-caspase 3 was activated. ABC294640 inhibited the expression of c-Myc in EOC. The in vivo assay showed an inhibitory effect of ABC294640 on tumor growth.

Conclusions: ABC294640 could downregulate the expression of c-Myc in EOC both in vitro and in vivo. ABC294640 inhibited tumor growth in EOC via cell cycle arrest and inducing cell apoptosis both in vitro and in vivo, partially by decreasing the expression of cell cycle-associated proteins (such as $P-\mathrm{Rb}$, cyclin $\mathrm{B} 1$, and cyclin $\mathrm{D} 1$ ) and promoting caspase 3 activation via downregulation expression of c-Myc. It suggested that ABC294640 had the potential to serve as an agent in EOC treatment.

Keywords: ABC294640, epithelial ovarian cancer, c-Myc, proliferation

\section{Introduction}

Ovarian cancer is associated with the worst prognosis among gynecological malignancies. In the United States, 22,400 women were diagnosed with epithelial ovarian cancer (EOC) in $2017 .^{1}$ Most patients $(\approx 65 \%)$ were diagnosed with stages III or $\mathrm{IV}^{2}$ and 14,080 women died because of EOC. ${ }^{1}$ In China, ovarian malignancies take the third place in the incidence of gynecological malignancies, just behind cervical malignant disease and uterine corpus cancer. ${ }^{3}$ EOC accounts for more than $80 \%$ of the ovarian cancer, ${ }^{4}$ with 52,100 new cases and with a high mortality rate. ${ }^{5}$
Correspondence: Wen Di; Lan Dai Department of Obstetrics and Gynecology, Ren Ji Hospital, School of Medicine, Shanghai Jiao Tong University, I60 Pujian Road, Pudong New District, Shanghai 200127, People's Republic of China

Email diwen163@163.com; delta496@I26.com 
According to an estimate from the American Cancer Society, patients with EOC had a poor survival with a 5year survival of $46 \%{ }^{6}$ Regrettably, in the last few decades, although the latest introduction of immunotherapy and targeted therapy brings new hopes for patients with EOC, but the 5-year survival rate has not been improved significantly with these agents. Therefore, new therapeutic targets and anticancer medicaments urgently need to be developed.

Sphingolipids, as membrane components, are ubiquitous in all eukaryotic cells. Known as important signaling molecules, sphingolipids are involved in regulating many key cellular functions. ${ }^{7}$ The activation of SphK leads to the phosphorylation of sphingosine to form sphingosine1-phosphate (S1P), which is a well-known key molecule in phospholipid metabolism. It can promote a number of malignant behaviors, including cell survival, migration, invasion, angiogenesis, differentiation, and immune cell modulation. ${ }^{8,9} \mathrm{SphK}$ is involved in the regulation of S1P metabolism and serves as a signaling molecule regulating tumor cell survival and apoptosis. SphK inactivation leads to the accumulation of S1P precursors, including reducing oncogene activity, bringing about cell apoptosis and growth arrest. ${ }^{8,10}$ Two subtypes of SphKs exist in mammals, SphK1 and SphK2. The role of SphK1 in tumorigenesis, cancer development, and chemotherapy resistance has received much attention. SphK1 has been considered as a prognostic marker for tumors. Also, the oncogenic role of SphK1 has been deeply studied in EOC. ${ }^{11,12}$ Another subtype of SphK, SphK2, plays a relatively complex role in tumor formation and development. The gene encoding the SphK2 locates on chromosome 19 (19q13.2). ${ }^{13}$ In normal cells, SphK2 plays a role in promoting cell apoptosis and inhibiting cell proliferation, while in malignant tumors, SphK2 can accelerate cell proliferation, inhibit cell apoptosis, and promote the progress of cancer. ${ }^{14-18}$ SphK2 is overexpression in many human cancers. It has been showed that low-level SphK2 overexpression could promote cell proliferation and survival. ${ }^{19}$

Lots of results support the use of SphK2-specific inhibitors as anti-cancer agents. In a range of cancer cell lines, targeting SphK2 has showed more effective anti-tumor effect than targeting SphK1. ${ }^{20}$ A small molecule inhibitor, ABC294640 has been described as a highly selective inhibitor of SphK2. ${ }^{21}$ Some recent studies showed that ABC294640 could suppress the growth of prostate, lung, rectum, breast, and pancreatic cancer. ${ }^{22,23}$ Meanwhile, ABC294640 showed the similar efficacy of chemotherapy in vivo without systemic toxicity. A phase I clinical trial of ABC294640 in patients with advanced solid tumors has been completed. It is worth highlighting that the result of that clinical trial demonstrates pharmacologic inhibition of SphK2 and anti-tumor activity of ABC294640. ${ }^{24}$ However, the possible role of $\mathrm{ABC} 294640$ in treating EOC and the potential signaling mechanisms has been poorly understood. Therefore, our study aimed to investigate the following: (1) whether the inhibitor of SphK2, ABC294640, inhibited EOC cell growth; (2) whether ABC294640 modulated the survival of EOC cells by altering cell cycle and apoptosis; (3) by which pathway, ABC294640 changed the biological behavior of EOC; and (4) whether ABC294640 had therapeutic activity with altering the state of tumor growth in vivo.

\section{Material and methods Cell lines and cell culture}

Human EOC cell line SKOV3 was purchased from the American Type Culture Collection (VA, USA). HO8910 was obtained from the Cell Bank of Chinese Academy of Sciences (Shanghai, China). The cells were tested to confirm no mycoplasma and no cross-contamination. They were cultured in DMEM medium (Hyclone, USA) with $10 \%$ fetal bovine serum (Gibco, USA) and 1\% penicillin/ streptomycin (Sigma, USA). They were incubated in a thermostatic humidified cell incubator with $5 \% \mathrm{CO}_{2}$ at $37^{\circ} \mathrm{C}$. All cells used in experiments underwent no more than 20 passages.

\section{Chemicals and antibodies}

ABC294640 and MG132 were provided by Selleck (Shanghai, China). ABC294640 and MG132 were dissolved in DMSO for further use. Antibodies against SphK2, GAPDH, and c-Myc were bought from Abcam (Cambridge, UK). Antibodies against cyclin D1, cyclin $\mathrm{B} 1, P-\mathrm{Rb}$, cleaved-caspase 3 and Bcl-2 were ordered from Cell Signaling Technology (Shanghai, China).

\section{Cell viability assay}

The CCK-8 assay from Dojindo (Kumamoto, Japan) was used to investigate the viability of EOC cells. SKOV3 and HO8910 cells were seeded in a 96-well plate with the density of $3 \times 10^{3}$ cells each well. Then, the cells were treated with ABC294640 at different concentrations up to $200 \mu \mathrm{M}$ or $0.1 \%$ DMSO (vehicle control) for $72 \mathrm{hrs}$. At the indicated time point, the original medium was 
removed, and $100 \mu \mathrm{L}$ of the medium with $10 \% \mathrm{CCK}-8$ solution was added to each well. After incubation at $37^{\circ} \mathrm{C}$ for $2 \mathrm{hrs}$, optical density (OD) values were measured in a microplate reader (Multiscan MK3; Thermo Scientific, USA). Then, the cell viability was calculated using the following formula: OD values of treated groups/OD values of vehicle control groups $\times 100 \%$. Finally, the $50 \%$ inhibitory concentration (IC50) value was determined using GraphPad Prism 5.0 (CA, USA).

\section{Colony formation assay}

SKOV3 and HO8910 cells were planted in six-well plates with the density of $1 \times 10^{3}$ cells per well. After incubated in the incubator overnight, cells were treated with 12.5 and $25 \mu \mathrm{M}$ ABC294640 in cell culture medium. The medium should be replaced with fresh medium containing ABC294640 every 3 days. Fourteen days later, the cells were fixed with $4 \%$ paraformaldehyde (Sangon Biotech, China) and stained with $1 \%$ crystal violet (Sangon Biotech, China). Then, the plates were gently washed with phosphate-buffered saline (PBS) and dried. Any colony more than 50 cells was counted as positive under an inverted microscope by manual (Olympus). Cell clonogenic survival was normalized to DMSO vehicle control.

\section{Cell cycle analysis}

For cell cycle analysis, SKOV3 and HO8910 cells were treated with $\mathrm{ABC} 294640 \quad(50 \mu \mathrm{M})$ for $48 \mathrm{hrs}$. Subsequently, they were collected and fixed overnight at $4^{\circ} \mathrm{C}$ with ice-cold $75 \%$ ethanol. After washing, $500 \mu \mathrm{L}$ propidium iodide (PI)/RNase staining solution (BD Bioscience, CA, USA) was added to the tubes with cells for incubation in the dark for 45 mins at room temperature. The FACScan flow cytometer from Beckman Coulter (CA, USA) was used to measure cell cycle distribution.

\section{Apoptosis assay}

The Annexin V-FITC/PI apoptosis detection kit (BD, USA) was used to perform the cell apoptosis analysis. SKOV3 and HO8910 cells were treated with ABC294640 $(50 \mu \mathrm{M})$ for 48 hrs. Subsequently, they were digested with $0.25 \%$ trypsin without EDTA and washed once with ice-cold PBS and once with ice-cold $1 \times$ binding buffer. Next, according to the protocol, cells were resuspended in $100 \mu \mathrm{L}$ of $1 \times$ binding buffer at the density of $1 \times 10^{6} / \mathrm{mL}$. The cells were double stained with $5 \mu \mathrm{L}$ of PI and $5 \mu \mathrm{L}$ of Annexin V-FITC solution in the dark and incubated for 30 mins at room temperature. Then, $400 \mu \mathrm{L}$ of binding buffer was added to the tubes. The fluorescence intensity was detected by FACScan flow cytometer.

\section{Quantitative real-time PCR}

TRIzol (Invitrogen, USA) was used to extract total RNA, which was reverse transcribed using the PrimeScript reverse transcription reagent kit (TaKaRa Bio, China) to obtain complementary DNAs (cDNAs). Amplification reactions were conducted using the SYBR Premix Ex Taq kit (TaKaRa Bio) and then on an ABI 7,500 real-time system (Applied Biosystems, USA). The sequences of the primers for amplifying the human genes $c-M y c, S p h K 2$ and $G A P D H$ (considered as housekeeping genes) were as follows: $c-M y c, 5^{\prime}$ CGAGGAGAATGTCAAGAGGCGAAC-3' (forward) and 5'-GCTTGGACGGACAGGATGTATGC-3' (reverse); Sph $K 2$, 5'-GGTTGCTTCTATTGGTCAATCC-3' (forward) and 5'-GTTCTGTCGTTCTGTCTGGATG-3' (reverse); GAPDH, 5'-CGGAGTCAACGGATTTGGTC-3' (forward) and 5'CCATGGGTGGAATCATATTGG-3' (reverse). SYBR Green RT-PCR was performed to measure mRNA levels. Using mean $\mathrm{Ct}$ values of the targeted genes, and paired $\mathrm{Ct}$ values of GAPDH as a loading control. The $2^{-\Delta \Delta \mathrm{Ct}}$ method was used to calculate the difference in mRNA expression.

\section{Small interfering RNA (siRNA) and transient transfection}

The chemically synthesized siRNAs targeting human SphK2 (5'-AACCUCAUCCAGACAGAACGA-3') and the control siRNA (5'-AAUUCUCCGAACGUGUCACGU-3') were ordered from GenePharma (Shanghai, China). Lipofectamine 2,000 (Invitrogen, USA) was used to perform the transfection of the specific siRNA. After $24 \mathrm{hrs}$ of transfection, the levels of the targeted genes were detected by qRT-PCR. Forty-eight hours later, the levels of the targeted genes were detected by Western blots.

\section{Western blot analysis}

The cells were lysed in RIPA lysis buffer (Beyotime, China) supplemented with protease inhibitor cocktail (MCE, USA). After sufficient lysis, the protein concentration of the sample was determined using BCA reagent (Sangon Biotech, China). After denaturing at $100^{\circ} \mathrm{C}$ for $10 \mathrm{mins}$, equal amounts of the lysates with $40 \mu \mathrm{g}$ of protein were separated using $10 \%$ or $12 \%$ standard SDS gel electrophoresis and then transferred to a PVDF membrane (Millipore, MA, USA). The membrane was blocked using Trisbuffered saline with $0.1 \%$ Tween 20 (TBST) containing 
$5 \%$ bovine serum albumin for $1 \mathrm{hr}$ at room temperature. The membranes were probed with the indicated primary antibodies in dilution buffer (Beyotime, China) at $4^{\circ} \mathrm{C}$. On the second day, the membranes were washed with TBST and incubated with anti-rabbit or anti-mouse immunoglobulin $\mathrm{G}$ horseradish peroxidase-conjugated secondary antibodies at room temperature for $1 \mathrm{hr}$. Finally, the proteins were visualized using the ECL Western blotting kit (Meilunbio, China). The relative gray scale of each protein was analyzed using the ImageJ software.

\section{Tumor xenograft model and treatment}

All animal experiments followed the guidelines of the Institutional Animal Care and Use Committee of Ren Ji Hospital, and all animal protocols were approved by the same committee. 4-6-week-old nude female mice were ordered from the Chinese Academy of Sciences. Each mouse was injected intraperitoneally with $3.5 \times 10^{6}$ SKOV3 cells in $200 \mu \mathrm{L}$ of PBS to establish intraperitoneal xenograft models. After 7 days, the mice were randomly divided into two groups: control group and ABC294640 treatment group ( $n=6$ in each group). ABC294640 was dissolved as a solution with a concentration of $5 \mathrm{mg} / \mathrm{mL}$ as follows: $2 \%$ DMSO $+30 \%$ PEG $300+5 \%$ Tween $80+$ PBS. The mice in the control group were injected intraperitoneally with an equivalent amount of DMSO in PBS (vehicle). The mice in the $\mathrm{ABC} 294640$ treatment group were treated with ABC294640 intraperitoneally at the dose of $50 \mathrm{mg} / \mathrm{kg}, 3$ times per week for 4 weeks. The mice were sacrificed 28 days after administering ABC294640 (35 days after injecting cancer cells). The difference in the number of visible tumors and the weight between the two groups was calculated. The maximum tumor in each mouse was immersed in tumor lysate and subjected to Western blot analysis, the rest was fixed in formalin and embedded in paraffin. The protein expression levels in tumors of the two groups were also detected through Western blot analysis and immunohistochemistry.

\section{Immunohistochemistry}

Formalin-fixed, paraffin-embedded specimens were used for immunostaining. Tumor sections were dewaxed and then rehydrated. The slides were heated near the boiling stage by microwave. After blocking, the slides were incubated with each primary antibody. Sections were then incubated with secondary antibody followed by treatment with 3, 3'-diaminobenzidine and counterstaining with hematoxylin.

Image acquisition and analysis: after immunoperoxidase labeling, the sections were observed through microscopy (DM 2500; Leica, Germany). All images were acquired and processed in TIFF format, analysis was done using Image ProPlus 6 AMS software. Protein expression intensity was assessed as the integrated optical density (IOD) by estimating the area of the objects and the medium pixel intensity per object. The same light level as for incidental light without a slide was kept for each image acquired.

\section{Statistical analysis}

All data were presented as mean \pm standard deviation (SD). Data were analyzed using the SPSS software version 24. The Student $t$ test was used for comparison between two groups. When the $P$-value was less than 0.05 , the difference was considered as statistically significant. Each experiment was performed independently in triplicate.

\section{Results}

\section{$A B C 294640$ inhibited the proliferation of EOC cells in vitro}

Different concentrations of ABC294640 (0-200 $\mu \mathrm{M})$ were used to treat SKOV3 and HO8910 cells for $72 \mathrm{hrs}$ to evaluate the effect of ABC294640 on EOC cell growth. The CCK-8 assay revealed that ABC294640 significantly reduced the cell viability of SKOV3 and HO8910 cells. A dose-dependent reduction in the viability was observed on EOC cell growth. The IC50 value of ABC294640 for 72 hrs was $36.91 \pm 6.61 \mu \mathrm{M}$ in SKOV3 cells and 29.41 $\pm 5.78 \mu \mathrm{M}$ in HO8910 cells (Figure 1A and B), suggesting that ABC294640 displayed a similar inhibitory effect on SKOV3 and HO8910 cells. In order to investigate the long-term effect of ABC294640 on the cell viability, we used the colony formation assay. ABC294640 treatment obviously inhibited colony formation of the SKOV3 and HO8910 cells at the concentration of $12.5 \mu \mathrm{M}$ and $25 \mu \mathrm{M}$, in a dose-dependent manner compared with the vehicle control group (Figure 1C and D). These data suggested that ABC294640 exerted a significant inhibitory effect on EOC cell proliferation. According to the IC50 value of ABC294640, the cells treated with $\mathrm{ABC} 294640$ at the concentrations 25 and $50 \mu \mathrm{M}$ were selected for subsequent investigation. 
A
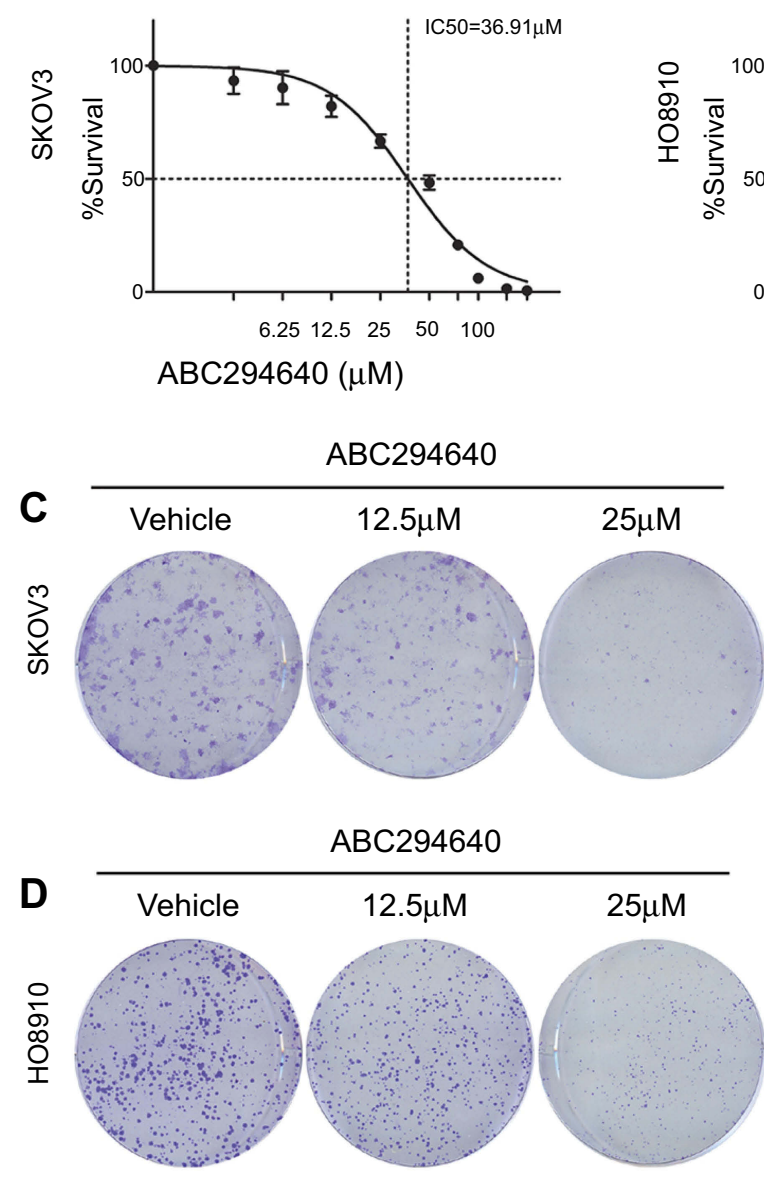

B
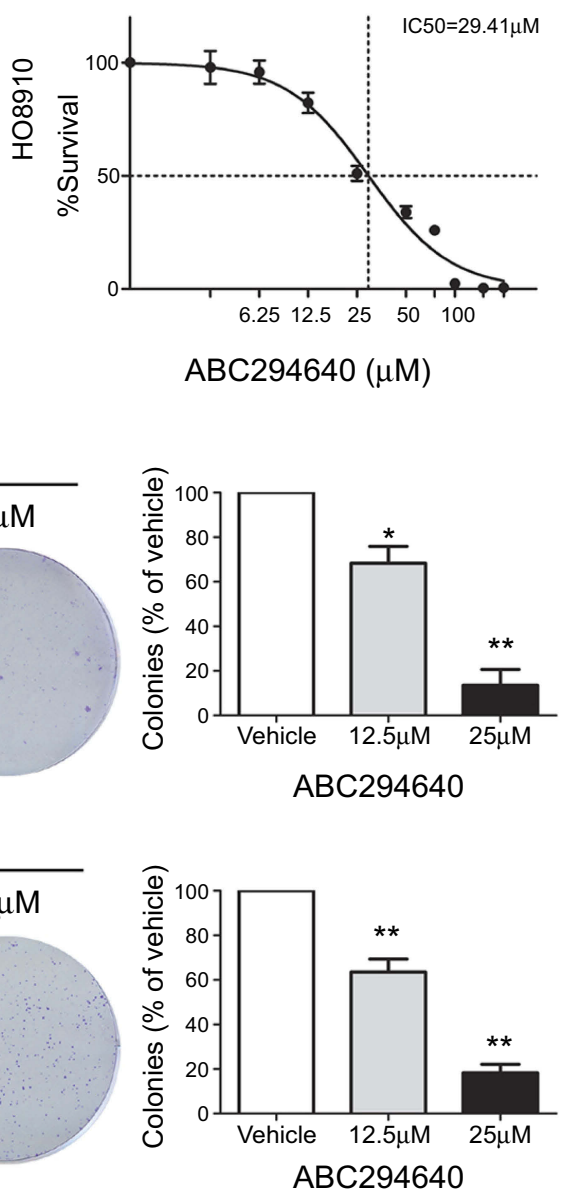

Figure I ABC294640 treatment inhibited the proliferation of EOC cell lines. (A and B) EOC cell lines SKOV3 and H089/0 were incubated with the indicated concentrations of $A B C 294640$ or $0.1 \%$ DMSO for 72 hrs. The cell proliferation was measured using the CCK-8 assay. Error bars represent the SD from three independent experiments. IC50 was calculated using GraphPad 5.0. (C and D) Cells were treated with 12.5 or $25 \mu M$ ABC294640 or $0.1 \%$ DMSO (vehicle control). The remaining cells were stained with crystal violet and quantified. The experiments were repeated three times. Data were shown as percent control of vehicle-treated wells. $* P<0.05$; $* * P<0.0$ I versus vehicle control.

Abbreviations: EOC, epithelial ovarian cancer; DMSO, dimethyl sulfoxide; CCK-8, cell counting kit-8.

\section{$A B C 294640$ induced cell cycle arrest in EOC cells}

The cell cycle distribution was analyzed using flow cytometry to further investigate the mechanism through which ABC294640 reduced EOC cell proliferation. The percent of cells treated with $\mathrm{ABC} 294640(50 \mu \mathrm{M})$ in S phase for $48 \mathrm{hrs}$ was significantly lower compared with that of cells in DMSO vehicle group (Figure 2A and B). The expression of several cell cycle checkpoint factors, including cyclin $\mathrm{D} 1, P-\mathrm{Rb}$, and cyclin B1 was determined by using Western blot analysis to explore the underlying molecular mechanism through which ABC294640 induced $\mathrm{S}$ phase cell cycle arrest. As the results, the expression levels of cyclin $\mathrm{D} 1, P-\mathrm{Rb}$, and cyclin $\mathrm{B} 1$ markedly reduced in ABC294640 treatment groups in a dosedependent manner (Figure 2C and D). These results proved that $\mathrm{ABC} 294640$ inhibited the proliferation of EOC cells by inducing cell cycle arrest.

\section{ABC294640 induced apoptosis in EOC cells}

Besides the alternation of cell cycle, apoptosis is also correlated with cancer cell proliferation. Annexin V-FITC/PI double staining could identify cell apoptosis. Hence, flow cytometry was performed to investigate whether ABC294640 treatment could impact the apoptosis of SKOV3 and HO8910 cells. ABC294640 $(50 \mu \mathrm{M})$ treatment for $48 \mathrm{hrs}$ caused apparent apoptosis in SKOV3 and HO8910 cells. Compared with vehicle control group, the apoptosis of EOC cells was observed after the treatment with ABC294640 (Figure 3A and B). In addition, the expression 

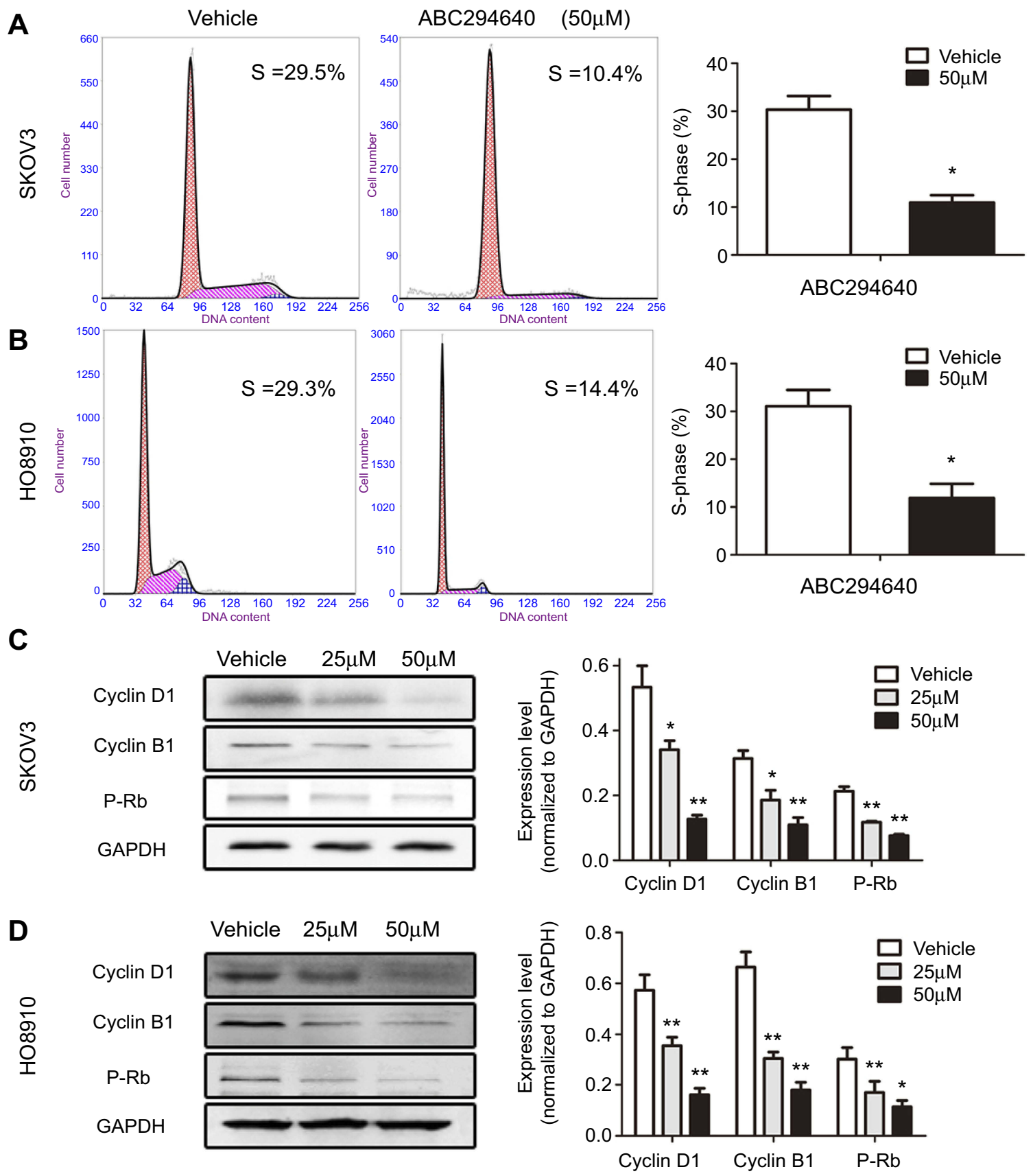

Figure 2 ABC294640 treatment caused cell cycle arrest in EOC cells. (A and B) SKOV3 and HO89I0 were incubated with $50 \mu M$ ABC294640 or $0.1 \% D M S O$ for 48 hrs, stained with propidium iodide (PI), and analyzed using flow cytometry. (C and $\mathbf{D})$ Protein expression was analyzed using immunoblot analysis. The experiments were repeated three times. The experiment results are shown. $* P<0.05 ; * * P<0.01$ versus vehicle control.

Abbreviations: EOC, epithelial ovarian cancer; PI, propidium iodide.

of crucial proteins involved in apoptosis, such as Bcl-2 and cleaved-caspase 3, was determined using Western blot to further explore the mechanism of cell apoptosis induced by $\mathrm{ABC} 294640$. As the results were shown in Figure 3C and D, the expression levels of Bcl-2 were markedly reduced in ABC294640 treatment groups with a dose-dependent manner. Conversely, the level of the cleaved form for caspase 3 raised with the increase of $\mathrm{ABC} 294640$ concentration. It proved that $\mathrm{ABC} 294640$ could advance the activation of caspase 3. The results in Figure 3 indicated that ABC294640 had great potential applications in inducing apoptosis in EOC cells. 
A

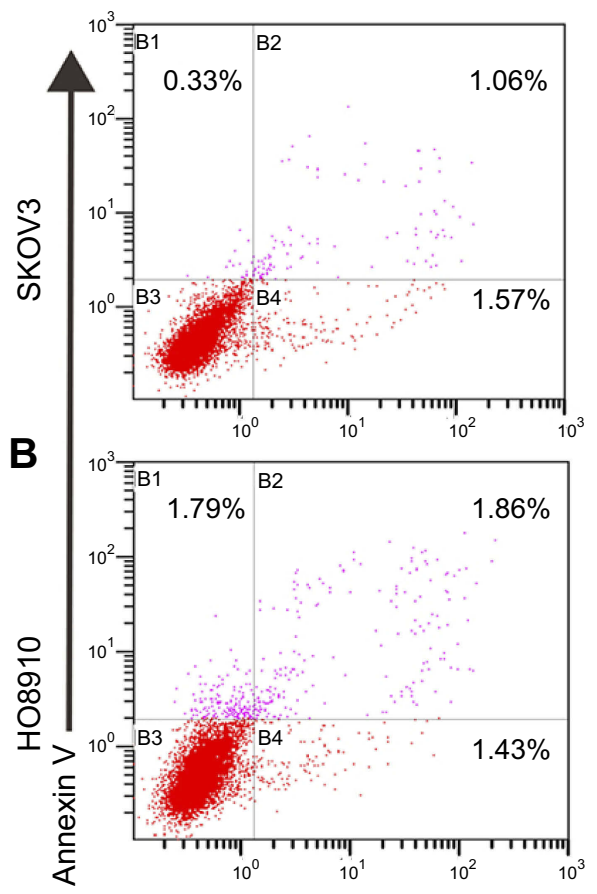

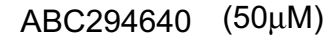
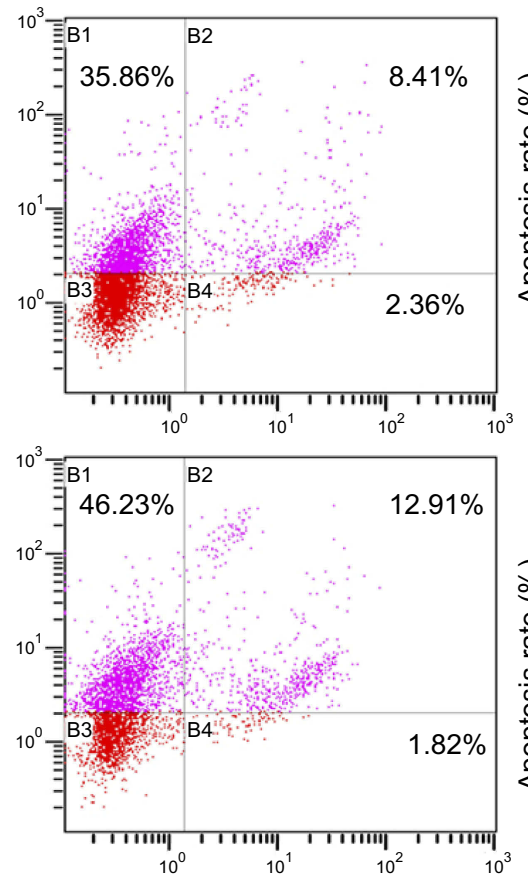

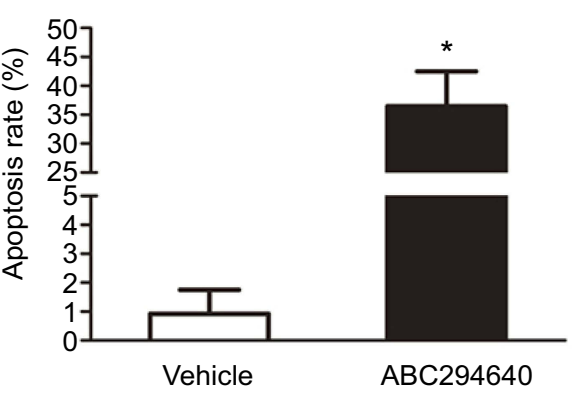

$\mathrm{PI}$

C
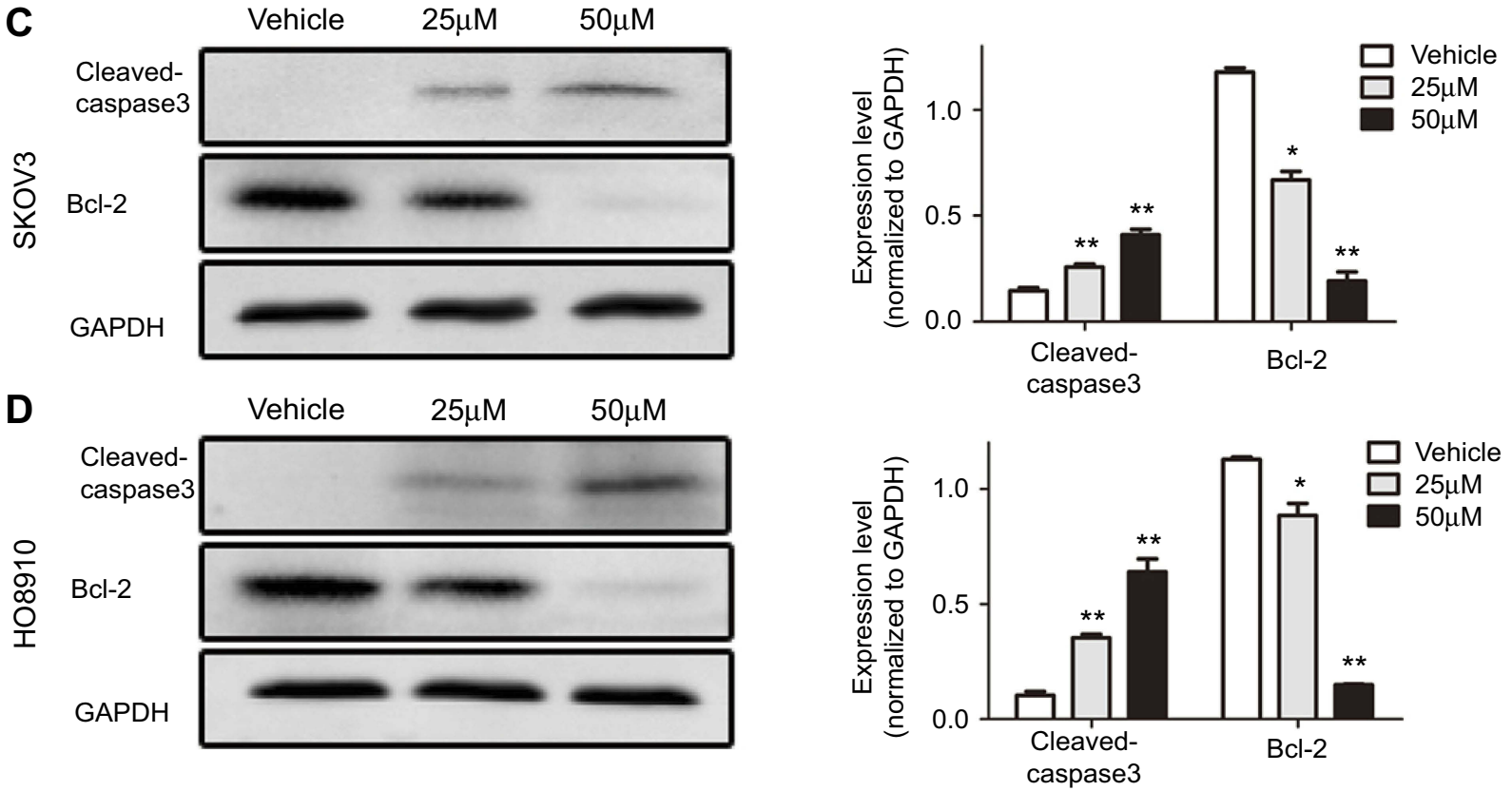

Figure 3 ABC294640 treatment induced EOC cell apoptosis. (A and B) SKOV3 and HO89I0 were incubated with $50 \mu M$ ABC294640 or $0.1 \%$ DMSO for 48 hrs. Cell apoptosis was measured using Annexin V/PI staining and flow cytometry analysis. (C and D) Protein expression was analyzed using immunoblot analysis. The experiments were repeated three times. Error bars represent the SD from three independent experiments. The experiment results are shown. $* P<0.05$; $* * P<0.01$ versus vehicle. Abbreviations: EOC, epithelial ovarian cancer; PI, propidium iodide.

\section{ABC294640 decreased the expression of c-Myc through enhancing c-Myc proteasome degradation}

For elucidating the underlying mechanism of ABC294640mediated EOC repression, the role of oncogene $c-M y c$ was investigated in our study. As the results shown in Figure 4A and $\mathrm{B}$, after treatment with various concentrations of ABC294640 for $48 \mathrm{hrs}$, the expression levels of c-Myc decreased dose-dependently. We tried to determine whether ABC294640 affected gene transcription of $c-M y c$. SKOV3 
A

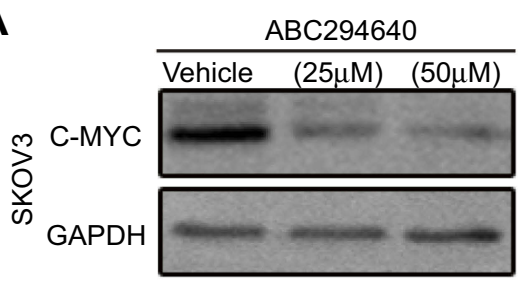

B

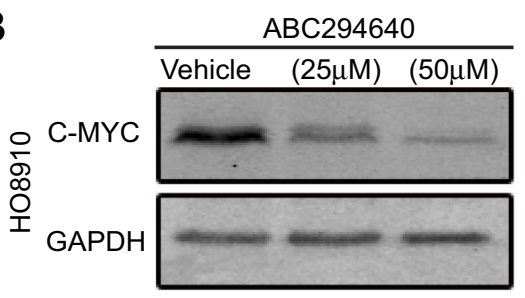

C

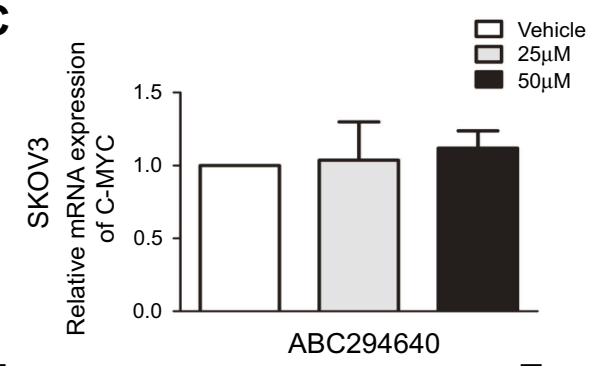

E

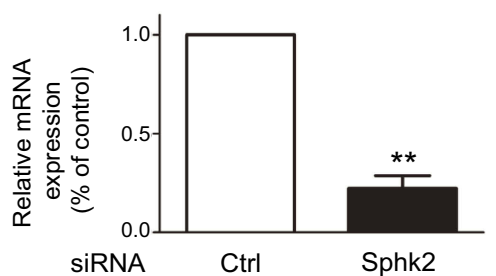

F

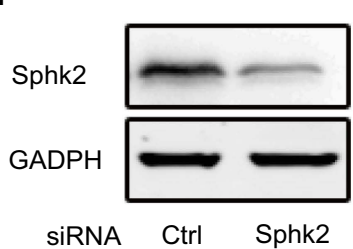

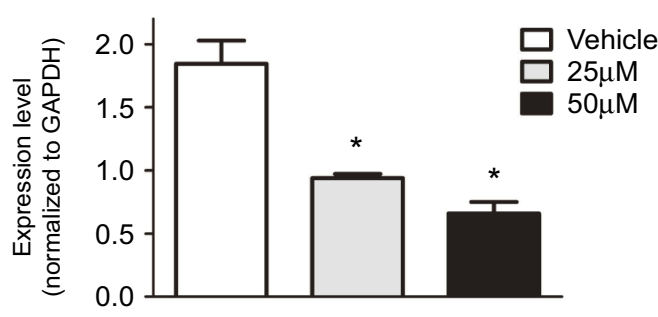

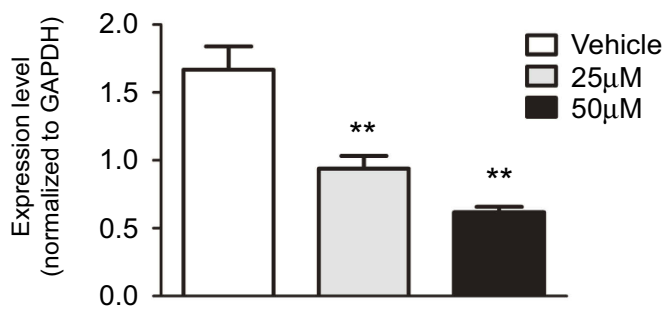

D

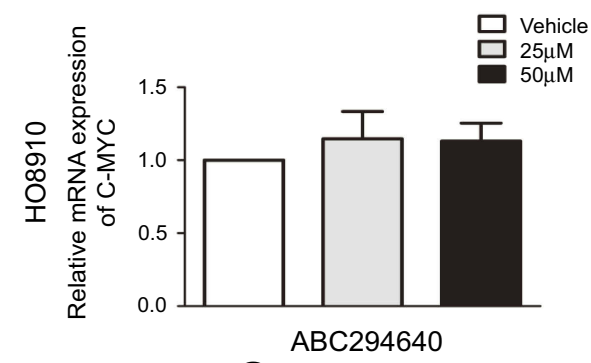

G

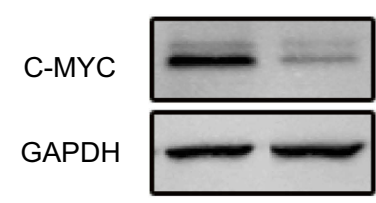

SiRNA Ctrl Sphk2

H

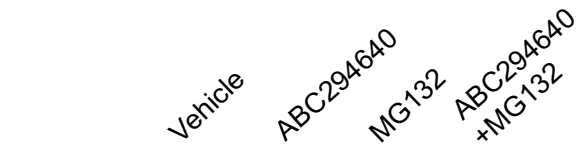

C-MYC

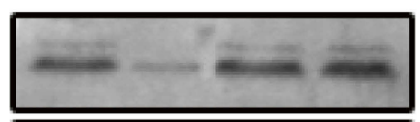

GAPDH
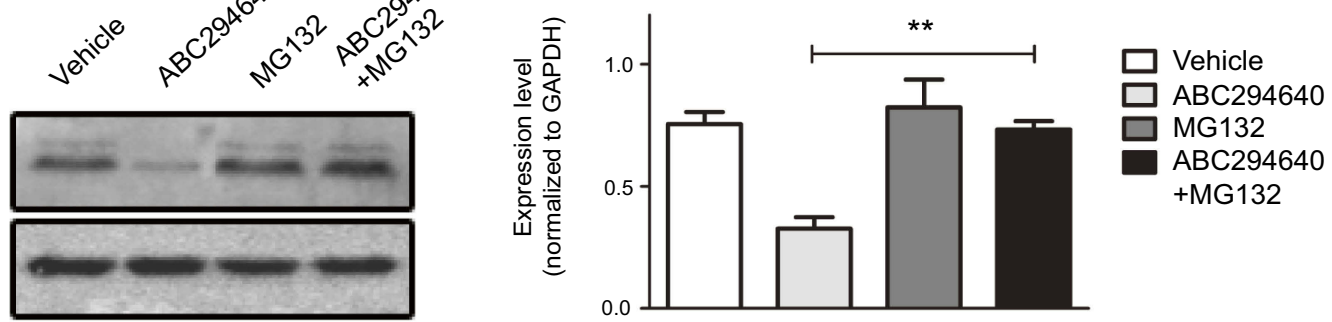

Figure 4 ABC294640 decreased the expression of c-Myc through enhancing c-Myc proteasome degradation. (A and B) The effect of $A B C 294640$ ( 25 and $50 \mu M)$ treatment for $48 \mathrm{hrs}$ on the protein expression of C-MYC in SKOV3 and HO8910 cells was measured using Western blot analysis. (C and D) The effect of ABC294640 ( 25 and $50 \mu M$ ) treatment for 24 hrs on the mRNA expression level of C-MYC in SKOV3 and HO89I0 cells was measured using qRT-PCR. (E) SKOV3 cells were transfected with controlsiRNA and SphK2-siRNA. Expression of SphK2 mRNA levels was determined by PCR and normalized to GAPDH mRNA. (F) Protein levels of SphK2 were determined by Western blot. (G) Western blot was used to detect the C-MYC protein level after the knockdown of SphK2 using siRNA in SKOV3. (H) SKOV3 cells were treated with $0.1 \%$ DMSO or MGI32 (5 $\mu$ M), followed by treatment with $0.1 \%$ DMSO or $50 \mu$ M ABC294640 for additional 48 hrs. The protein expression of c-Myc in SKOV3 cells was measured using western blot analysis. Error bars represent the SD from three independent experiments. The experiment results are shown. $* P<0.05$; $* * P<0.01$ versus control.

Abbreviations: siRNA, small interfering RNA; Ctrl, control.

and HO8910 cells were treated with ABC294640 or DMSO for $24 \mathrm{hrs}$, and the expression of $c-M y c$ mRNA was quantified using qRT-PCR. Different from protein expression levels, ABC294640 did not affect $c-M y c$ gene transcription (Figure 4C and D), indicating that $\mathrm{ABC} 294640$ did not downregulate $c-M y c$ expression at the transcriptional level. The expression level of c-Myc was downregulated by administration of ABC294640 in EOC cells. In order to further prove the relationship between SphK2 and c-Myc expression, we used specific siRNA for knockdown the 
expression of SphK2. We found that following SphK2 knockdown, the expression of c-Myc protein decreased significantly (Figure 4E, F and G). The protein expression is controlled by the rate of biosynthesis and degradation. Protein degradation has an equally important role as biosynthesis in regulating protein expression. On the basis of the fact that $\mathrm{ABC} 294640$ did not alter c-Myc transcription, we further investigated whether $\mathrm{ABC} 294640$ increased the rate of c-Myc degradation. In SKOV3, the expression of c-Myc was investigated in different groups, $0.1 \% \mathrm{DMSO}$ vehicle buffer, treated with ABC294640 alone, MG132 (proteasome inhibitor) alone, and a combination of ABC294640 with MG132. The study showed that MG132 reproducibly protected c-Myc from degradation induced by ABC294640 (Figure 4H). Thus, the result suggested, at least in part, that $\mathrm{ABC} 294640$ accelerated c-Myc degradation. The above data indicated that $\mathrm{ABC} 294640$ did not affect the rate of $c-M y c$ gene transcription, but enhanced the proteasome degradation of c-Myc to achieve the decrease in the expression of c-Myc.

\section{ABC294640 inhibited EOC tumor growth in mouse xenograft models}

The effect of ABC294640 was assessed using mouse xenograft models to further explore whether it could inhibit the growth of EOC in vivo. SKOV3 cells were injected intraperitoneally in the nude mice. After 7 days of injection of SKOV3, the mice were randomly divided into 2 groups. One group was treated with $\mathrm{ABC} 294640(50 \mathrm{mg} / \mathrm{kg}$ intraperitoneally, three times per week), another group was treated with vehicle control buffer for 4 weeks. At the end of this experiment, we found that $\mathrm{ABC} 294640$ injection resulted in significantly decreased both tumor number and tumor weight (Figure 5B and C). Moreover, we have noticed that neither mice died nor significant difference in the body weight was observed between untreated and experimental treatment groups (Figure 5A). It suggested that ABC294640 administration caused non-toxic side effects. Furthermore, for the tumor tissue of each mouse, cell cycle- and apoptosis-related proteins were characterized by Western blot and immunohistochemical analysis. Consistent with the results in vitro, ABC294640 administration significantly reduced the expression of cyclin $\mathrm{D} 1$, cyclin $\mathrm{B} 1$, and $P-\mathrm{Rb}$, indicating cell cycle arrest (Figure 5D). The decrease of $\mathrm{Bcl}-2$ expression and the rise of cleaved-caspase 3 (Figure 5D) proved that ABC294640 also induced tumor cell apoptosis in vivo. The study also evaluated the difference in c-Myc expression between two groups. As shown in Figure 5D, ABC294640 downregulated c-Myc expression in vivo. Our results of immunohistochemical staining furtherly confirmed that $\mathrm{ABC} 294640$ administration inhibited the expression of cyclin $\mathrm{D} 1$, cyclin $\mathrm{B} 1, P-\mathrm{Rb}$, and Bcl-2 (Figure 5E). These results suggested that ABC294640 inhibited EOC tumor growth in vivo by repressing c-Myc expression, which induced cell cycle arrest and cell apoptosis in mouse xenograft models.

\section{Discussion}

This study focused on the therapeutic effect of $\mathrm{ABC} 294640$ on EOC. It showed that ABC294640, the selective inhibitor of SphK2, displayed anti-tumor activities in EOC. Importantly, the data proved that the intraperitoneal administration of a well-tolerated dose $(50 \mathrm{mg} /$ $\mathrm{kg}$ ) of ABC294640 effectively inhibited SKOV3 xenograft in vivo. Moreover, in ovarian cancer cell lines SKOV3 and HO8910, ABC294640 caused cell apoptosis and cell cycle arrest by down-regulating cell cycle-associated proteins (cyclin $\mathrm{D} 1$, cyclin $\mathrm{B} 1$, and $P-\mathrm{Rb}$ ) and activating apoptosisassociated protein caspase 3. ABC294640 inhibited tumor proliferation through inhibiting the expression of oncogene c-Myc (an important transcription factor regulating apoptosis and cell cycle) and accelerating its degradation. The findings suggested that targeting of SphK2 by ABC294640 could potently inhibit epithelial ovarian cancer growth in vitro and in vivo. These data together have provided new evidence that $\mathrm{ABC} 294640$ might have broad prospects for clinical applications in EOC.

Evading growth suppressors and sustaining proliferative signaling are described as the most important characteristic among 10 hallmarks of neoplastic diseases. ${ }^{25}$ The present study showed that the percent of cells in the S phase was significantly reduced in cell lines treated with ABC294640, implying that ABC294640 caused cell cycle arrest in the S phase in ovarian cancer (Figure 2A and B). This study showed that ABC294640 inhibited EOC cell survival by blocking cell cycle. Cell proliferation is controlled by the activation of the checkpoints of cell cycle. If the cell receives interference from external factors during DNA synthesis and chromosomal segregation, it leads to the inhibition of activation of cyclin-dependent kinases and cell cycle arrest. Cell cycle-associated proteins, such as cyclin B1 and cyclin D1, could accelerate cell proliferation by driving the cell cycle. ${ }^{26}$ Cyclin D1 is one of the most important members in the cyclin protein family. Cyclin D1 promotes $\mathrm{G} 1$ to the $\mathrm{S}$ phase transformation in cell cycle by forming a complex like cyclin D1/CDK4. Therefore, cyclin 
A

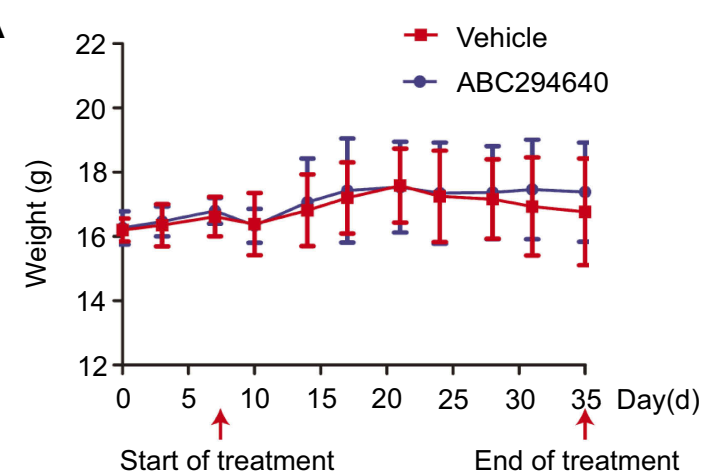

B

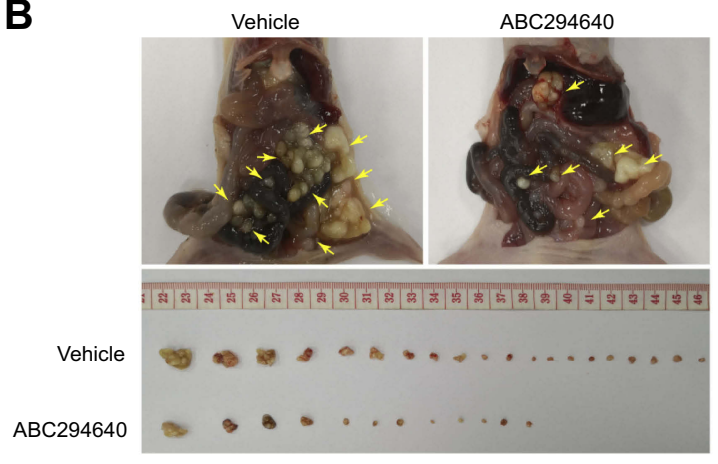

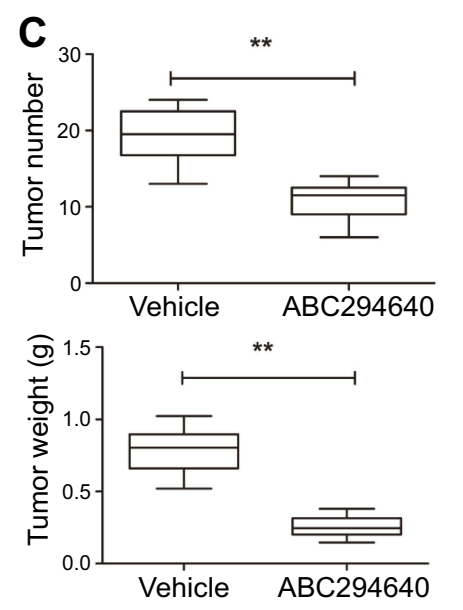

D
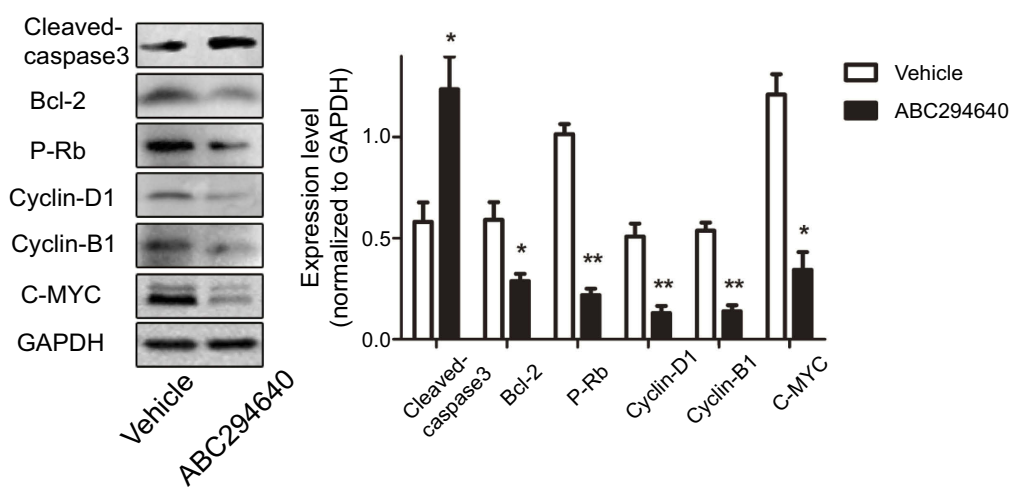

E
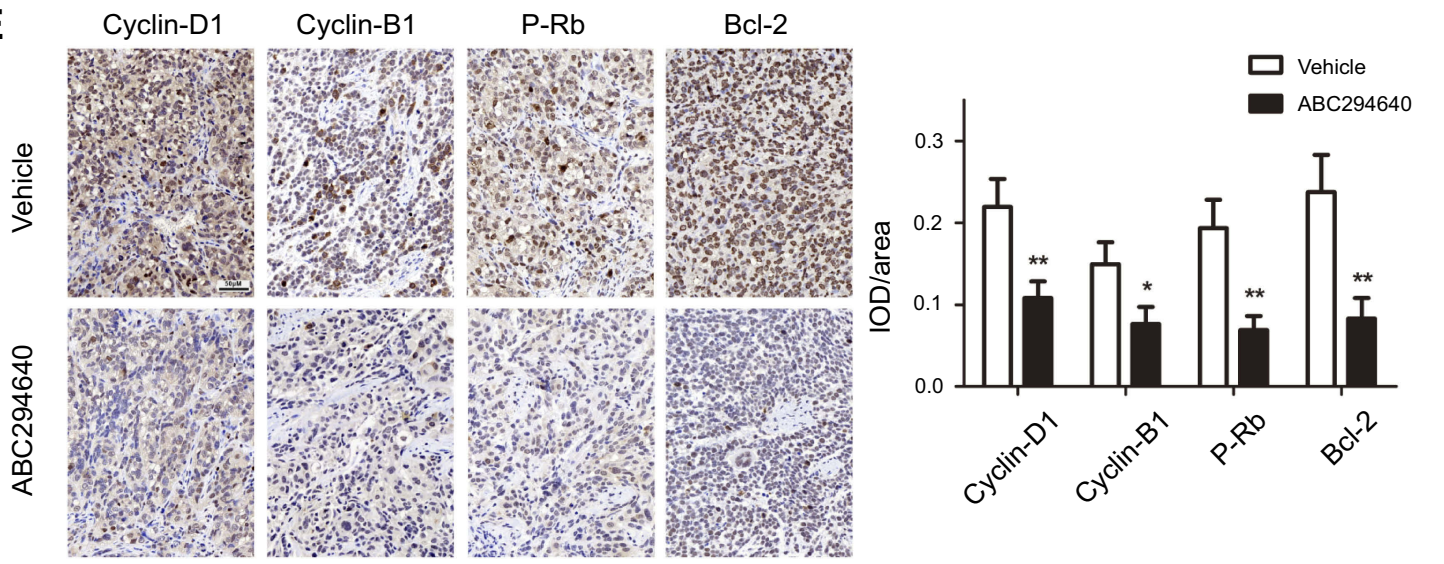

Figure 5 ABC294640 inhibited EOC tumor growth in mouse xenograft models. (A) Body weight was monitored during the detectable period in nude mice. (B) Typical images of disseminated tumors in intraperitoneal ovarian cancer xenograft model treated with vehicle control buffer or $A B C 294640$. (C) Whole tumor number and tumor weight in intraperitoneal ovarian cancer xenograft model treated with vehicle control buffer $(n=6)$ or $A B C 294640$ ( $n=6)$ were quantified in nude mice. (D) Expression levels of the indicated proteins in xenograft tumor tissues for two groups were quantified using Western blot analysis. (E) Expression levels of the indicated proteins in xenograft tumor tissues for two groups were quantified using immunohistochemistry. Original magnification, $\times 200$. Representative blots from 6 mice per group with identical observations. $* P<0.05 ; * * P<0.01$ versus vehicle control.

Abbreviation: EOC, epithelial ovarian cancer.

D1 is regarded as rate-limiting for G1/S transition. ${ }^{27-29}$ Furthermore, cyclin D1 binds to and activates CDK4/CDK6 to phosphorylate the protein $\mathrm{Rb}$. The phosphorylation of $\mathrm{Rb}$ leads to the subsequent release of E2F1 and then pushes the transition of cell cycle to the $\mathrm{S}$ phase. ${ }^{30}$ The cyclin D1/P-Rb pathway was inhibited by $\mathrm{ABC} 294640$ in vivo and in vitro (Figures 2C, D and 5D, E). The transition from the G1 phase to the $\mathrm{S}$ phase in EOC cells was blocked with the reduction of cell percentage in the S phase. The results of this study showed that ABC294640 suppressed the expression of cyclin B1 with the same performance in vitro and in vivo (Fig 2C, $\mathrm{D}$ and 5D, E). Previous studies indicated that cyclin B1 was a key molecule in cancer cell aggressive proliferation. The expression level of cyclin B1 is correlated with the cell 
growth rate, and the decrease in expression of cyclin B1 led to growth arrest in vivo. ${ }^{31}$ For instance, the findings of the present study demonstrated that ABC294640 treatment led to the stagnation of cell cycle and inhibition of cancer cell proliferation.

Resisting cell death is described as another hallmark of neoplastic diseases. ${ }^{25}$ Apoptosis is a form of programmed cell death, which can be induced by a series of physical and chemical factors. Chemical agents who induce cancer cell apoptosis are considered to be potential anticancer drugs. ${ }^{32}$ The percentage of apoptotic cells was measured using flow cytometry and the expression of apoptosis-associated proteins was detected using Western blot analysis to investigate whether ABC294640 could induce apoptosis in EOC cells. The results of in vitro experiments showed that ABC294640 induced cell apoptosis; experiments in SKOV3 and HO8910 cells yielded the same results (Figure $3 \mathrm{~A}$ and $\mathrm{B}$ ). The results in vitro and in vivo indicated that $\mathrm{ABC} 294640$ induced EOC cell apoptosis, inhibited the expression of $\mathrm{Bcl}-2$, and increased the expression of cleaved-caspase 3 (Figure 3C, D and 5D, E). Caspase 3 is an effector caspase protein that has the most important role in the mitochondria-mediated cell death pathway. Activated caspase 3 interferes DNA repair to induce cell apoptosis. 9 According to the findings of the present study, the increase in caspase 3 cleavage indicated that caspase 3 was activated by fragmentation during ABC294640 treatment-induced apoptosis in EOC cells. ABC294640 inhibited Bcl-2 expression in a dose-dependent manner. Unlike other oncoproteins that promote cell growth and proliferation, $\mathrm{Bcl}-2$ is found to promote tumorigenesis through cell death resistance. ${ }^{33}$ Similar to a previous study, the anticancer effect of ABC294640 in ovarian cancer cell line was achieved by inducing apoptosis through potentiating Bcl-2-associated X-protein level. ${ }^{34}$ This study further confirmed that ABC294640 increased the expression of cleaved caspase 3 , and reduced the expression of Bcl-2 in vivo, which was consistent with the results in vitro. Taken together, ABC294640 induced EOC cell apoptosis, and the in vivo investigation further suggested that ABC294640 might be potentially applied in clinical EOC treatment. Further investigations are warranted in this regard.

Our results suggested that ABC294640 inhibited tumor proliferation by blocking cell cycle and inducing cell apoptosis. On the other hand, a previous study on acute lymphoblastic leukemia (ALL) showed that the knockdown of SphK2 decreased the expression of c-Myc. ${ }^{16}$ It has been well documented that c-Myc transcription factor regulates numerous malignant cell processes, including cell cycle progression, metastasis, epithelial-mesenchymal transition, and angiogenesis in many types of cancer. ${ }^{35}$ Among multiple malignancies, such as breast cancer, prostate cancer, lung cancer, and ovarian cancer, excessive activation of c-Myc is thought to be involved in tumorigenesis and tumor development. $^{36}$ The overexpression of c-Myc protein is likely to promote the process of malignancy and tumor progression. ${ }^{37}$ High c-Myc expression is associated with high recurrence, poor overall survival, and cisplatin resistance in these patients with high-grade serous ovarian cancer. ${ }^{38}$ Downregulation of c-Myc may furnish a potential opportunity for EOC therapy. The downregulation of c-Myc expression could downregulate the expression of cyclin D1 simultaneously, affecting cell cycle progression. ${ }^{39-41}$ ABC294640 reduced the expression of Cyclin D1 in EOC. For these reasons and given the close relationship between cyclin D1 and c-Myc, it is suspected the anticancer effect of ABC294640 is achieved by regulating c-Myc. Thus, the expression of c-Myc after ABC294640 treatment was detected using Western blot analysis. As a result, the expression of c-Myc was significantly inhibited by ABC294640 dose-dependently (Figure 4A, B and 5D, E). It was consistent with previous data, which showed that ABC294640 downregulated c-Myc expression in multiple myeloma cells, pancreatic cancer cells, prostate cancer cells, and ALL cells. ${ }^{14,16,17,23,42}$ Since the drug that can directly inhibit c-Myc as a target has not yet been successfully synthesized, the most practical approach to ablating the tumorigenic effects of c-Myc is targeting upstream regulators to reduce the expression and activity of c-Myc. Hence, it is meaningful that, ABC294640, as a suppressor of SphK2, could inhibit the expression of c-Myc at the protein level in tumors. Our studies also showed that the knockdown of SphK2 by RNA interference (RNAi) reduced the expression of c-Myc (Figure 4G). The regulation of SphK2 on c-Myc in ovarian cancer needs further study. It was noteworthy that the mRNA level of c-Myc did not change significantly after treatment with ABC294640 (Figure 4C and D). As the protein expression was determined by the equilibrium between synthesis and degradation, this study tried to determine whether the degradation of c-Myc was increased by ABC294640. The study found that with the application of MG132 could, partially, reverse the downregulation of c-Myc protein expression mediated by ABC294640 (Figure 4H), and it suggested that ABC294640 reduced the expression of c-Myc at the protein level at least in part via increasing proteasome degradation pathway. 
In addition, the phase I clinical trial on the role of ABC294640 in advanced solid tumors has been completed recently. ${ }^{24}$ The $500 \mathrm{mg}$ bid dose level of ABC294640 was chosen as the recommended dose in phase II clinical trial because it was well tolerated by patients and reached biologically relevant plasma concentration. The findings indicated that $\mathrm{ABC} 294640$, as an SphK2-targeted therapy, may have broad prospects for clinical applications in EOC.

\section{Conclusions}

In conclusion, this study showed that $\mathrm{ABC} 294640$ could significantly inhibit EOC growth by causing cell cycle stagnation and inducing caspase-dependent apoptosis both in vitro and in vivo, which was closely related to the downregulated expression of c-Myc at the protein level. These findings provided the foundations for future exploration of this small-molecule inhibitor for the treatment of epithelial ovarian cancer.

\section{Ethics approval and informed consent}

All animal experiments followed the guidelines of the Institutional Animal Care and Use Committee of Ren Ji Hospital, and all animal protocols were approved by the same committee.

\section{Data availability}

The datasets used and/or analyzed during the current study are available from the corresponding author on reasonable request.

\section{Abbreviations}

EOC, epithelial ovarian cancer; OD, optical density; S1P, sphingosine-1-phosphate.

\section{Acknowledgments}

This work was supported by National Natural Science Foundation of China (Grant No. 81772770 to Wen Di and 81402128 to Lan Dai), Shanghai Municipal Commission of Health and Family Planning (No. 2017YQ035 to Lan Dai), Science and Technology Commission of Shanghai Municipality (Grant No. 18ZR1423100 to Lan Dai). The funders had no role in study design, data collection and analysis, decision to publish, or preparation of the manuscript.

\section{Author contributions}

All authors contributed to data analysis, drafting and revising the article, gave final approval of the version to be published, and agree to be accountable for all aspects of the work.

\section{Disclosure}

The authors report no conflicts of interest in this work.

\section{References}

1. Siegel RL, Miller KD, Jemal A. Cancer statistics, 2017. CA Cancer J Clin. 2017;67(1):7-30. doi:10.3322/caac.21387

2. Narod S. Can advanced-stage ovarian cancer be cured? Nat Rev Clin Oncol. 2016;13(4):255-261. doi:10.1038/nrclinonc.2015.224

3. Teng Z, Han R, Huang X, et al. Increase of incidence and mortality of ovarian cancer during 2003-2012 in Jiangsu Province, China. Front Public Health. 2016;4:146. doi:10.3389/fpubh.2016.00146

4. Hou M, Cheng Z, Shen H, et al. High expression of CTHRC1 promotes EMT of epithelial ovarian cancer (EOC) and is associated with poor prognosis. Oncotarget. 2015;6(34):35813-35829. doi:10.18632/oncotarget.5358

5. Chen W, Zheng R, Baade PD, et al. Cancer statistics in China, 2015. CA Cancer J Clin. 2016;66(2):115-132. doi:10.3322/caac.21338

6. Olawaiye AB, Java JJ, Krivak TC, et al. Does adjuvant chemotherapy dose modification have an impact on the outcome of patients diagnosed with advanced stage ovarian cancer? An NRG oncology/gynecologic oncology group study. Gynecol Oncol. 2018;151(1):18-23. doi:10.1016/j.ygyno.2018.07.021

7. Pyne S, Bittman R, Pyne NJ. Sphingosine kinase inhibitors and cancer: seeking the golden sword of hercules. Cancer Res. 2011;71 (21):6576-6582. doi:10.1158/0008-5472.CAN-11-2364

8. Ogretmen B, Hannun YA. Biologically active sphingolipids in cancer pathogenesis and treatment. Nat Rev Cancer. 2004;4(8):604-616. doi:10.1038/nrc1411

9. Takabe K, Paugh SW, Milstien S, Spiegel S. "Inside-out" signaling of sphingosine-1-phosphate: therapeutic targets. Pharmacol Rev. 2008;60(2):181-195. doi:10.1124/pr.107.07113

10. Shida D, Takabe K, Kapitonov D, Milstien S, Spiegel S. Targeting SphK1 as a new strategy against cancer. Curr Drug Targets. 2008;9 (8):662-673.

11. Dai L, Liu Y, Xie L, Wu X, Qiu L, Di W. Sphingosine kinase 1/ sphingosine-1-phosphate (S1P)/S1P receptor axis is involved in ovarian cancer angiogenesis. Oncotarget. 2017;8(43):74947-74961. doi:10.18632/oncotarget.20471

12. Zhang H, Wang Q, Zhao Q, Di W. MiR-124 inhibits the migration and invasion of ovarian cancer cells by targeting SphK1. J Ovarian Res. 2013;6(1):84. doi:10.1186/1757-2215-6-84

13. Liu H, Sugiura M, Nava VE, et al. Molecular cloning and functional characterization of a novel mammalian sphingosine kinase type 2 isoform. J Biol Chem. 2000;275(26):19513-19520. doi:10.1074/jbc. M002759200

14. Venkata JK, An N, Stuart R, et al. Inhibition of sphingosine kinase 2 downregulates the expression of c-Myc and Mcl-1 and induces apoptosis in multiple myeloma. Blood. 2014;124(12):1915-1925. doi:10.1182/blood-2014-03-559385

15. Wang Q, Li J, Li G, et al. Prognostic significance of sphingosine kinase 2 expression in non-small cell lung cancer. Tumour Biol. 2014;35(1):363-368. doi:10.1007/s13277-013-1051-1

16. Wallington-Beddoe CT, Powell JA, Tong D, Pitson SM, Bradstock KF, Bendall LJ. Sphingosine kinase 2 promotes acute lymphoblastic leukemia by enhancing MYC expression. Cancer Res. 2014;74(10):2803-2815. doi:10.1158/0008-5472.CAN-13-2732 
17. Lewis CS, Voelkel-Johnson C, Smith CD. Suppression of c-Myc and RRM2 expression in pancreatic cancer cells by the sphingosine kinase-2 inhibitor ABC294640. Oncotarget. 2016;7(37):60181-60192. doi:10.18632/oncotarget.11112

18. Xun C, Chen MB, Qi L, et al. Targeting sphingosine kinase 2 (SphK2) by ABC294640 inhibits colorectal cancer cell growth in vitro and in vivo. $J$ Exp Clin Cancer Res. 2015;34:94. doi:10.1186/s13046-015-0205-y

19. Neubauer HA, Pitson SM. Roles, regulation and inhibitors of sphingosine kinase 2. FEBS J. 2013;280(21):5317-5336. doi:10.1111/ febs. 12314

20. Van Brocklyn JR, Jackson CA, Pearl DK, Kotur MS, Snyder PJ, Prior TW. Sphingosine kinase-1 expression correlates with poor survival of patients with glioblastoma multiforme: roles of sphingosine kinase isoforms in growth of glioblastoma cell lines. J Neuropathol Exp Neurol. 2005;64(8):695-705.

21. French KJ, Zhuang Y, Maines LW, et al. Pharmacology and antitumor activity of ABC294640, a selective inhibitor of sphingosine kinase-2. $J$ Pharmacol Exp Ther. 2010;333(1):129-139. doi:10.1124/ jpet.109.163444

22. Lewis CS, Voelkel-Johnson C, Smith CD. Targeting sphingosine kinases for the treatment of cancer. Adv Cancer Res. 2018;140:295-325. doi:10.1016/bs.acr.2018.04.015

23. Venant H, Rahmaniyan M, Jones EE, et al. The sphingosine kinase 2 inhibitor ABC294640 reduces the growth of prostate cancer cells and results in accumulation of dihydroceramides in vitro and in vivo. $\mathrm{Mol}$ Cancer Ther. 2015;14(12):2744-2752. doi:10.1158/1535-7163.MCT15-0279

24. Britten CD, Garrett-Mayer E, Chin SH, et al. A phase I study of $\mathrm{ABC} 294640$, a first-in-class sphingosine kinase-2 inhibitor, in patients with advanced solid tumors. Clin Cancer Res. 2017;23 (16):4642-4650. doi:10.1158/1078-0432.CCR-16-2363

25. Hanahan D, Weinberg RA. Hallmarks of cancer: the next generation. Cell. 2011;144(5):646-674. doi:10.1016/j.cell.2011.02.013

26. Chen ZM, Huang L, Li MM, Meng L, Ying SC, Xu AM. Inhibitory effects of isocryptotanshinone on gastric cancer. Sci Rep. 2018;8 (1):9307. doi:10.1038/s41598-018-27638-0

27. Diehl JA. Cycling to cancer with cyclin D1. Cancer Biol Ther. 2002;1(3):226-231.

28. Kahl CR, Means AR. Regulation of cyclin D1/Cdk4 complexes by calcium/calmodulin-dependent protein kinase I. $J$ Biol Chem. 2004;279(15):15411-15419. doi:10.1074/jbc.M312543200

29. Musgrove EA, Lee CS, Buckley MF, Sutherland RL. Cyclin D1 induction in breast cancer cells shortens G1 and is sufficient for cells arrested in G1 to complete the cell cycle. Proc Natl Acad Sci U S A. 1994;91(17):8022-8026.
30. Tashiro E, Maruki H, Minato Y, Doki Y, Weinstein IB, Imoto M. Overexpression of cyclin D1 contributes to malignancy by up-regulation of fibroblast growth factor receptor 1 via the $\mathrm{pRB} /$ E2F pathway. Cancer Res. 2003;63(2):424-431.

31. Yuan J, Kramer A, Matthess Y, et al. Stable gene silencing of cyclin B1 in tumor cells increases susceptibility to taxol and leads to growth arrest in vivo. Oncogene. 2006;25(12):1753-1762. doi:10.1038/sj. onc. 1209202

32. Elmore S. Apoptosis: a review of programmed cell death. Toxicol Pathol. 2007;35(4):495-516. doi:10.1080/01926230701320337

33. Hockenbery D, Nunez G, Milliman C, Schreiber RD, Korsmeyer SJ. $\mathrm{Bcl}-2$ is an inner mitochondrial membrane protein that blocks programmed cell death. Nature. 1990;348(6299):334-336. doi:10.1038/ $348334 \mathrm{a} 0$

34. White MD, Chan L, Antoon JW, Beckman BS. Targeting ovarian cancer and chemoresistance through selective inhibition of sphingosine kinase-2 with ABC294640. Anticancer Res. 2013;33 (9):3573-3579.

35. Dang CV, O‘Donnell KA, Zeller KI, Nguyen T, Osthus RC, Li F. The c-Myc target gene network. Semin Cancer Biol. 2006;16(4):253-264. doi:10.1016/j.semcancer.2006.07.014

36. Cole MD, Nikiforov MA. Transcriptional activation by the Myc oncoprotein. Curr Top Microbiol Immunol. 2006;302:33-50.

37. Wei S, Shen X, Lai L, et al. FSH receptor binding inhibitor impacts K-Ras and c-Myc of ovarian cancer and signal pathway. Oncotarget. 2018;9(32):22498-22508. doi:10.18632/oncotarget.25 139

38. Liu X, Yu Y, Zhang J, et al. HDAC1 silencing in ovarian cancer enhances the chemotherapy response. Cell Physiol Biochem. 2018;48 (4):1505-1518. doi:10.1159/000492260

39. Fernandez PC, Frank SR, Wang L, et al. Genomic targets of the human c-Myc protein. Genes Dev. 2003;17(9):1115-1129. doi:10.1101/gad.1067003

40. Menssen A, Hermeking H. Characterization of the c-MYC-regulated transcriptome by SAGE: identification and analysis of c-MYC target genes. Proc Natl Acad Sci U S A. 2002;99(9):6274-6279. doi:10.1073/pnas.082005599

41. Miliani de Marval PL, Macias E, Rounbehler R, et al. Lack of cyclin-dependent kinase 4 inhibits c-myc tumorigenic activities in epithelial tissues. Mol Cell Biol. 2004;24(17):7538-7547. doi:10.1128/MCB.24.17.7538-7547.2004

42. Schrecengost RS, Keller SN, Schiewer MJ, Knudsen KE, Smith CD. Downregulation of critical oncogenes by the selective SK2 inhibitor ABC294640 hinders prostate cancer progression. Mol Cancer Res. 2015;13(12):1591-1601. doi:10.1158/1541-7786.MCR14-0626
OncoTargets and Therapy

\section{Publish your work in this journal}

OncoTargets and Therapy is an international, peer-reviewed, open access journal focusing on the pathological basis of all cancers, potential targets for therapy and treatment protocols employed to improve the management of cancer patients. The journal also focuses on the impact of management programs and new therapeutic
Dovepress

agents and protocols on patient perspectives such as quality of life, adherence and satisfaction. The manuscript management system is completely online and includes a very quick and fair peer-review system, which is all easy to use. Visit http://www.dovepress.com/ testimonials.php to read real quotes from published authors. 